\title{
Enhanced Activity for Methanol Electro-oxidation on PtRu/C Catalyst by Reduction Treatment
}

\author{
Qi Wang,", Hualong Tao, Zhiqiang Li, Liu Shanshan, Lei Han \\ College of Materials Science and Engineering, Dalian Jiaotong University, Dalian 116028, Liaoning, \\ China \\ *E-mail: qiwang@djtu.edu.cn
}

doi: $10.20964 / 2017.07 .62$

Received: 29 March 2017 / Accepted: 9 May 2017 / Published: 12 June 2017

\begin{abstract}
Modified ethylene glycol method was used to synthesize PtRu/C catalyst which then annealed at different temperatures in hydrogen atmosphere. By X-ray diffraction, scanning and transmission electron microscopy, energy dispersive spectroscopy and inductively coupled plasma atomic emission spectroscopy, the structure and composition of catalysts were analyzed; Simultaneous thermal analysis tests gave the mass loss and thermal effect of the catalysts. Electrochemical methods were used to evaluate electro-catalytic activity of the catalysts towards $\mathrm{CO}$ and methanol electro-oxidation. The results showed that the average particle size and PtRu alloy crystallinity increased during the reduction treatment. Most of the surface adsorption species were removed after reduction treatment at $300{ }^{\circ} \mathrm{C}$ due to the decomposition temperature ranges of $110 \sim 220{ }^{\circ} \mathrm{C}$. The catalyst with reduction treatment at $300{ }^{\circ} \mathrm{C}$ exhibited the highest electrocatalytic activities, which was attributed to the removal of adsoption species, the increase of crystallinity and the formation of grain boundary.
\end{abstract}

Keywords: PtRu/C; reduction treatment; electro-catalytic acitivity; methanol electro-oxidation; CO tolerance

\section{$\underline{\text { FULL TEXT }}$}

(C) 2017 The Authors. Published by ESG (www.electrochemsci.org). This article is an open access article distributed under the terms and conditions of the Creative Commons Attribution license (http://creativecommons.org/licenses/by/4.0/). 